\title{
POST-RADIATION MEMORY CORRECTION USING DIFFERENTIAL SUBTRACTION FOR PHENIX*
}

\author{
C. L. Britton, Jr., A. L. Wintenberg, M. Womac, E. J. Kennedy, \\ R. S. Smith, G. R. Young, and T. C. Awes \\ Oak Ridge National Laboratory, Oak Ridge, TN 37831
}

\author{
Abstract and Summary Submissions for: \\ IEEE Nuclear Science Symposium \\ San Francisco, CA \\ October 21-28, 1995
}

\begin{abstract}
" The submitted manuscript has been authorized by a contractor of the U.S. Govemment under contract No. EDAC05840R21400. Accordingly, the U.S. Government retains a non-exclusive, royaltyfree license to publish or reproduce the published form of this contribution, or allow others to do so, for U.S. Government purposes."
\end{abstract}

*Research sponsored by the U.S. Department of Energy and performed at Oak Ridge National Laboratory, managed by Martin Marietta Energy Systems, Inc. for the U.S. Department of Energy under Contract No. DE-AC05-84OR21400.

\section{DISCLAIMER}

This report was prepared as an account of work sponsored by an agency of the United States Government. Neither the United States Government nor any agency thereof, nor any of their employees, makes any warranty, express or implied, or assumes any legal liability or responsibility for the accuracy, completeness, or usefulness of any information, apparatus, product, or process disclosed, or represents that its use would not infringe privately owned rights. Reference herein to any specific commercial product, process, or service by trade name, trademark, manufacturer, or otherwise does not necessarily constitute or imply its endorsement, recom. mendation, or favoring by the United States Government or any agency thereof. The views and opinions of authors expressed herein do not necessarily state or reflect those of the United States Government or any agency thereof. 


\section{DISCLAIMER}

Portions of this document may be illegible in electronic image products. Images are produced from the best available original document. 


\title{
Post-Radiation Memory Correction Using Differential Subtraction for PHENIX
}

\author{
C. L. Britton, Jr., A. L. Wintenberg, M. Womac*, E. J. Kennedy*, R. S. Smith*, \\ G. R. Young, and T. C. Awes
}

Oak Ridge National Laboratory and ${ }^{*}$ The University of Tennessee

In colliders such as RHIC, the radiation levels are well below those of colliders such as LHC. The problem is that there can be enough radiation at the inner detector (Multiplicity-Vertex Detector or MVD) to significantly affect a low-priced, nonradiation-hard CMOS process. If the radiation affects the entire analog memory in a uniform fashion, then a real-time correction should be able to be performed to correct any changes seen in the memory and also the induced correlated noise from detector pickup thus precluding the need for a more expensive rad-hard process. This paper will present testing on memories fabricated in a 'soft' process and exposed to ionizing radiation. We used a single pipeline as a reference to be subtracted in a cell-by-cell basis from each pipe during read out and investigated the spatial effects of using different pipes for the reference. Use of this method reduced the noise which was common to all pipes (common-mode noise) and thus reduced both common-mode input noise and pattern noise generated from address lines being exercised on the AMU. The correlation across the memories (6-, 8-, and 16-channel AMUs fabricated in the Orbit 1.2 $\mu$ CMOS process) vs. radiation dose was found to be quite good. Both pre-and post-radiation results are presented on systems designed for PHENIX and WA98 at CERN as well as measured results on the minimization of the effects of injected systematic noise.

\section{Corresponding author:}

\section{L. Britton}

Oak Ridge National Laboratory

P. O. Box 2008, MS 6006

Oak Ridge, TN 37831-6006

Phone 615-574-1878

britton@icsun1.ic.ornl.gov

\section{Suggested areas:}

Analog and Digital Circuits

Radiation effects on circuits

\author{
Presentation: \\ Oral or poster presentation.
}




\title{
Post-Radiation Memory Correction Using Differential Subtraction for PHENIX
}

\author{
C. L. Britton, Jr., A. L. Wintenberg, M. Womac*, E. J. Kennedy*, R. S. Smith*, \\ G. R. Young, and T. C. Awes
}

Oak Ridge National Laboratory and *The University of Tennessee

\section{Summary}

Real detector electronics systems have a variety of noise sources. These sources include pickup from the detector and associated input wiring, random noise from the preamplifier, pattern noise from the digital circuitry controlling the data acquisition system, and power-supply-induced noise from other circuits on the front-end boards. In addition, electronics such as vertex tracking systems that are close to the beam pipe in colliders can be damaged due to radiation exposure.

There has been little reported on the subject of radiation-hardened analog memory units (AMUs) [1, 2, 3]. In colliders such as RHIC, the radiation levels are well below those of colliders such as LHC. The problem is that there can be enough radiation at the inner detector (Multiplicity-Vertex Detector or.MVD) to significantly affect a low-priced, non-radiation-hard CMOS process. If the radiation affects the entire analog memory in a uniform fashion, then a real-time correction should be able to be performed to correct any changes seen in the memory and also the induced correlated noise from detector pickup thus precluding the need for a more expensive rad-hard process. Some work has been performed on differential subtraction $[4,5,6]$ but not with emphasis on radiation effects. This paper will present testing on memories fabricated in a 'soft' process and exposed to ionizing radiation. We used a single pipeline as a reference to be subtracted on a cell-bycell basis from each pipe during read out and investigated the spatial effects of using different pipes for the reference. Use of this method reduced the noise which was common to all pipes (common-mode noise) and thus reduced both common-mode input noise and pattern noise generated from address lines being exercised on the AMU. The correlation across the memories (6-, 8-, and 16-channel AMUs fabricated in the Orbit $1.2 \mu$ CMOS process) vs. radiation dose is quite good as can be seen in Fig. 1. This figure shows the resultant rms memory variation of pipeline number 1 after subtracting each cell of the pipeline shown on the $\mathrm{x}$-axis from pipeline number 1 for $0-, 25-, 50$-, and $75 \mathrm{KRad}$ ionizing radiation. The operation can be written symbolically as

$$
v_{\text {pipe,cell }}^{\text {rms }}=r m s\left[v_{\text {pipe,cell }}-v_{\text {reference,cell }}\right]
$$

where pipe is the pipeline being corrected, reference is the pipeline used for correction, cell is the given cell in the pipeline, and $r m s$ is the root-mean-square operation upon the array of numbers generated from the cell-by-cell subtraction for a given pipeline. As is obvious, the correlation across the chip is excellent. Figure 2 shows the pre- and post- 
radiation memory output variations using pipeline number 4 as a correction for the other 7 pipelines after $75 \mathrm{KRad}$ ionizing radiation. Both pre-and post-radiation results will be presented on systems designed for PHENIX and WA98 at CERN as well as measured results on the minimization of the effects of injected systematic noise.

\section{References}

[1] C. L. Britton, et al., "An Analog Random-Access Memory in the AVLSI-RA Process for an Interpolating Pad Chamber", IEEE Transactions on Nuclear Science (to be published).

[2] L. Jones, et al., "APV5-RH - A 128 Channel Analogue Pipeline for LHC", Presented at the 1994 IEEE Nuclear Science Symposium, Norfolk, Va., Nov. 1994.

[3] P. Murray, et al., "APC3RH - A Charge Sampling Analogue Buffer Chip for Silicon Detectors", Presented at the 1994 IEEE Nuclear Science Symposium, Norfolk, Va., Nov. 1994.

[4] J. T. Walker, et al., "Microstore - The Stanford Analog Memory Unit", IEEE Trans. Nucl. Sci., Vol. NS-32, No. 1, Feb. 1985, 616-621.

[5] Gunther Haller, private communication.

[6] H. Cunitz, et al., "A High-Rate, Precision Calorimetry Readout", Proc. of the International Conference on Electronics for Future Colliders, May 11-12, 1994, pp. 19-30.

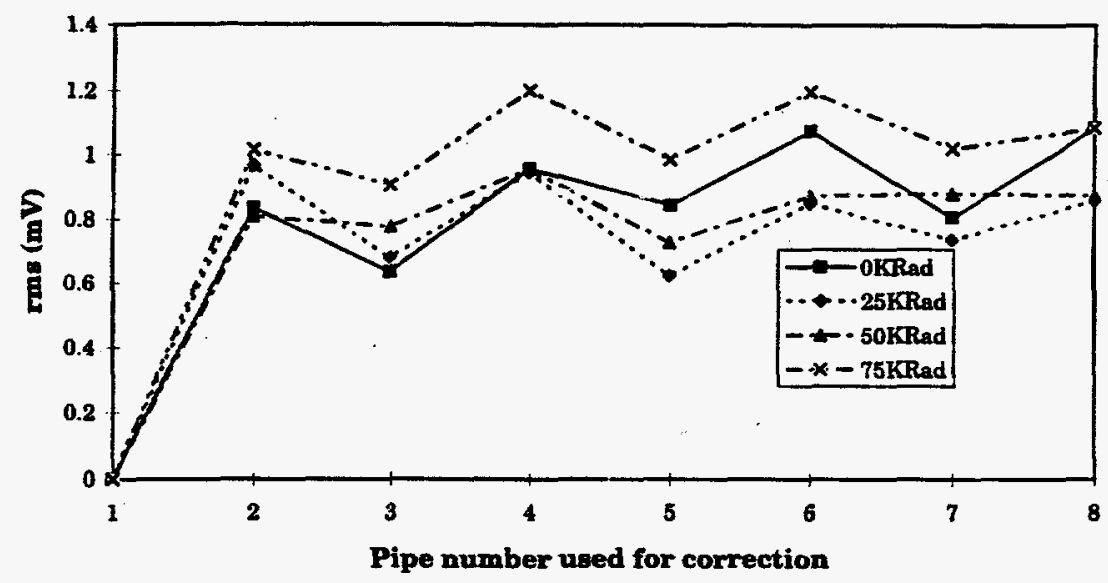

Figure 1. Thin Glenn chip 1, pipe 1 values, $0.5 V-0.5 V$

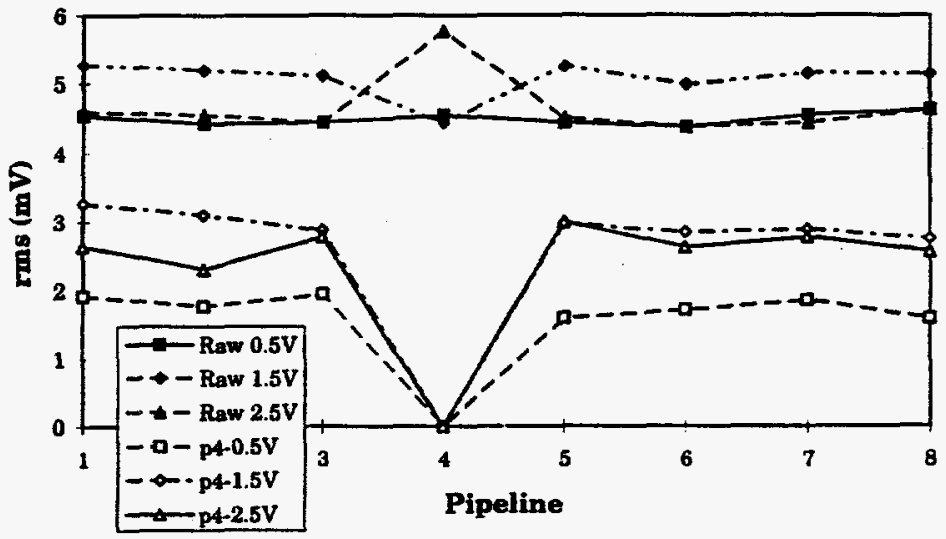

Figure 2. Chip 1, 75KRad, channel 4 as reference with $0.5 \mathrm{~V}$ input. 